\title{
Neo-structuralist analysis of green-marketing discourse: interpreting hybrid car manufacturers and consumers
}

\section{Djavlonbek Kadirov \& Richard J. Varey}

To cite this article: Djavlonbek Kadirov \& Richard J. Varey (2013) Neo-structuralist analysis of green-marketing discourse: interpreting hybrid car manufacturers and consumers, Consumption Markets \& Culture, 16:3, 266-289, DOI: 10.1080/10253866.2012.668367

To link to this article: https://doi.org/10.1080/10253866.2012.668367

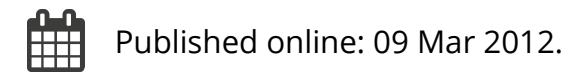

Submit your article to this journal ¿

Lll Article views: 1356

Q View related articles $\square$

7 Citing articles: 15 View citing articles 4 


\title{
Neo-structuralist analysis of green-marketing discourse: interpreting hybrid car manufacturers and consumers
}

\author{
Djavlonbek Kadirov $^{\mathrm{a} *}$ and Richard J. Varey ${ }^{\mathrm{b}}$ \\ ${ }^{a}$ Business School, Eastern Institute of Technology, New Zealand; ${ }^{b}$ Department of Marketing, \\ University of Waikato, New Zealand
}

To explain inconsistent behaviour that is well documented in green-marketing and consumption, the authors develop the (neo)structuralist model of meaning cocreation that is based on the signifying practices of hybrid car manufacturers and consumers. The model reveals that market agents are recruited into a symbolic order that requires the perpetual reinforcement of self-opposing meanings as a condition for signification. The main problem of green practice is not the issue of market agents' authenticity/hypocrisy. Rather it represents a more interactive phenomenon - the common structure of meaning-creation - which silences important transformative action choices and thus defeats its own purpose.

Keywords: culture; meaning; structure; symbolic order; hybrid cars; green-marketing

From the perspective of social critics and independent observers, the greatest concern regarding green-marketing is that it is all talk and no trousers. Market participants display behavioural inconsistency. Real-world corporate action tends to be more or less in contradiction to the ideals of environmental care espoused by brands and managers (Kangun and Polonsky 1995; Welford 1997; Smith 1998). Similarly, consumers report an increasing concern about environmental issues but fail to make consistent choices (Reidenbach and Oliva 1983; Heiskanen and Pantzar 1997; Schor 1999; Connolly and Prothero 2003; Kjellberg 2008). There are two facets to this problem. On the one hand, market participants willing to engage in green behaviour are inhibited by the complexity and indeterminacy of environmental issues (Newholm 2005). In this regard, a stream of research has examined the so-called "attitude/behaviour gap" that signifies inconsistency between consumer intentions and their buying behaviours (Carrigan and Attalla 2001; Newholm 2005; Valor 2008). On the other hand, market participants in fact engage in green practices but are judged to be inauthentic in their action. For instance, some corporations are accused of greenwashing - a tendency to use limited responses to environmental issues as a means of generating greater cash flows (Welford 1997) through increased consumption. Similarly, consumers use green consumption as a means of constructing elitist identities (Crane 2000; Dolan 2002). These cases manifest a general phenomenon - inconsistency - as seen from an independent observer's position.

The approach we take is holistic as we scrutinise both producer and consumer practices and how they are linked. To do this, the (neo)structuralist notion of structure in

*Corresponding author. Email: dkadirov@eit.ac.nz

(C) 2013 Taylor \& Francis 
general (Levi-Strauss 1963; Barthes 1972; Frank 1989; Nöth 1990) and Lacan's symbolic order in particular (Belsey 2002; Lacan 2002; Žižek 2007) are brought into the discussion. Here, structure refers to an invariant pattern found in the signification (i.e. meaning-making) practices of market participants. Symbolic order refers to the structure of meaning-making practices that is based on implicit norms, conventions, rules, and regulations that an individual absorbs with language (Lacan 2002). In essence, we argue that behavioural inconsistency is the essential foundation of underlying meaning-making structure (i.e. symbolic order) co-created by marketers and consumers in interaction.

The purpose of this article is to develop a holistic model of meaning co-creation that comprises the signification practice of both corporations and consumers in the context of online green discourses. The motive is to explain why greening activities are often judged to be inconsistent. Here, we suspect the workings of a symbolic order, a unique culture expressed via contextualized structure, which organizes meaning-creation and, at the same time, necessitates self-contradictory action. We begin with examining a body of diverse literature on symbolism, structuralism, and neo-structuralism. We then develop a model of structural meaning co-creation based on our observation of online discourses in the domains of marketing and consumption of hybrid cars. We loop back to the discussion of behavioural inconsistency to understand the underlying structural roots of this phenomenon.

\section{The death of cultural authority}

Giving a historical account of consumer culture and branding, Holt (2002) argued that modern branding, which was dominant until the 1960s, was driven by cultural authority assumptions. Influenced by Linton's (1945) seminal formulation of culture as "the way of life of its members; the collection of ideas and habits which they learn, share and transmit from generation to generation" (203), the cultural authority model assumed that marketers can take charge of creating meanings to be widely shared and transmitted in society. This would involve engineering a limited set of meanings and identities only accessible through their brands. Within this paradigm, companies adopt green-marketing as a competitive strategy and differentiate their goods/services on the basis of environmentally "friendly" attributes. Moreover, these companies assume the role of the greening expert and educate customers on how they should construe eco-responsible lives with respect to the use of their brands. From the cultural authority point of view, green-marketing is the solution for consumers' wider social concerns about the deleterious impact of mainstream marketing culture (Crane 2000). Green behaviour results from consumers' reflective resistance to the cultural authority of corporations promoting wasteful lifestyles (Murray and Ozanne 1991), and their search for alternative eco-efficient solutions, and eventual acceptance of solutions authored by the same marketers or their competitors.

Holt (2002) shows that increasing recognition of consumer sovereignty led marketers to reconsider modern branding approaches. The idea of consumer sovereignty (Smart 2010) crept into the definitions of culture, for instance, Arnould and Thompson (2005) argued that (market) culture is the meaningful way of construing a personal life in relation to material/service resources available through market exchanges. In this respect, Holt (2002) shows that the assumptions behind the cultural authority model do not hold when it comes to describing postmodern branding and consumer culture which became dominant after the 1960s. Instead of directly engineering brand 
meanings, marketers started positioning brands as cultural resources that genuinely symbolize consumer-generated popular meanings. By incorporating cultural expressions independently created by the public (e.g. urban youth, consumption communities, cultural critics, and anti-corporate movements) into a branding network, marketers carefully crafted the corporate image of a genuine community member (Holt 2002). Applying Holt's perspective to green-marketing, one realizes that the death of cultural authority is expressed in branding strategies which tap into the rich domain of consumer-mediated discourse to derive brand meanings while recognizing the futility of engineering green attributes and lifestyles. The alternative branding strategies involve building upon meanings created by popular pundits, user communities, and product champions, and then feeding them back to the market under a business sponsored label. Naturally, the question of authenticity arises as consumers would like to "walk backstage to see the (sic) what the wizard is doing behind the scrim and to make sure that his character is consistent with what is presented onstage" (Holt $2002,86)$. The question raised here is fundamental in green-marketing as it relates to behavioural inconsistency judgements made in reference to corporations. Indeed, if companies absorb popular cultural meanings and commercialize them, then behavioural inconsistency (inauthenticity) judgements are unavoidable. However, if one looks at the same interactivity between consumers and producers from a different angle (e.g. neostructuralism), then $\mathrm{s} /$ he comes to realize that behavioural inconsistency, i.e. inauthenticity, is the very basis (i.e. structure, order) of producing "green" meanings.

In this article, we show an alternative perspective that supports Holt's thesis (2002), albeit taking a completely different route to conceptualize and analyse meaning, that the cultural authority model is irrelevant. We argue that meaning refers to potentialities in interaction and discourse which constitute structure. Once an agent is recruited into the symbolic order of green practice, he/she follows the structured path of meaningmaking.

Next, we discuss the structuralist and neo-structuralist conceptions of market culture. These insights in turn are employed in analysing online discourses about a specific green product, hybrid cars.

\section{The structuralist perspective}

Structuralism generally focuses on systems, and in particular, on structure within a theoretically delineated system (e.g. language, art, kinship, food preparation). Structure refers to an invariant element, the pattern of regularity, or a form of order in dynamic systems. Structuralist analysis is synchronic (i.e. the analysis of the current snapshot) rather than diachronic (i.e. the analysis of historical evolution through time). The belief in the absolute universality of structure is the key principle - a similar organization can be found across different cultures.

Structuralism is of two different forms: linguistic structuralism and general structuralism (Nöth 1990). According to linguistic structuralists, people perceive and organize their reality through and in language signs, whereas general structuralists extend the principles of text structuralism into non-linguistic phenomena. The father of linguistic structuralism, Saussure (1966) defined the single unit of structure, a sign, as the combination of signifier and signified. Signified refers to a concept in mind, while signifier denotes the "sound-image" of the concept. Saussure (1966) argued that signifier and signified are inseparable, although the signifier-signified link can be quite arbitrary. To understand the link, the structure of the whole system of signs needs to be 
grasped. As discussed by Nöth (1990), Saussure argued that only the community of people in interaction is capable of creating and modifying such links which in essence are cultural codes. According to Nöth, no individual agent has power to modify meanings fixed by language. As Mick (1986) explains, Saussure believed that the agency and power belongs to interactivity, while individual agents face the reality that has already been structured by language. Hence, the structure of market culture, the Big Other (Lacan 2002), will always be present before people start making meanings.

Extending Saussure's model, Hjelmslev (1943) developed the theory of connotation-denotation and metasemiotic. He argued that denotation consists in basic signification, that is, the relation of expression (signifier) to content (signified), which is called a denotative relation. Connotation refers to the content that has the denotative relation as its expression. Metasemiotic is the expression that has the denotative relation as its content. Barthes (1967) illustrated these on a box format (Figure 1).

Figure 1 shows the basic forms of signification. However, cultural meanings are complex; a single sign contains several layers of connotation or metasemiotic. The transition from one layer to another is dynamic and volatile. Fixing a single denotative relation is simply a starting point, while this relation in itself might contain the complex structure of connotation. Hence, meaning-creation is the work of community. From this perspective, one realizes that the cultural authority model focuses on an isolated snapshot of a complex system. The interdependence between signs is explored by Levi-Strauss (1963) in his analysis of kinship relationships. Kinship patterns, just like signs, appear to be organized as a whole system where the meaning of a particular relationship is derived with reference to other relationships. Also, LeviStrauss (1963) argued that structure is manifested in binary oppositions such as nature/culture, bad/good, man/woman. These oppositions reflect underlying societal conflicts. Myths are created and employed as strategies to resolve symbolic contradictions.

\section{Neo-structuralist perspectives}

The impossibility of one-way culture creation is evident in the writings of neo-structuralists, ${ }^{1}$ namely Barthes, Derrida, Foucault, Lacan, Althusser, Žižek, and Lyotard, who extend the structuralist project. Although the neo-structuralists critiqued Saussure and Levy-Strauss, disagreeing among each other on their re-readings of structuralism, Belsey (2002) indicates that a common structuralist theme underlies their writings.

\section{Connotation}

\begin{tabular}{|c|c|c|c|c|}
\hline Secondary Sign: & Connotation & Expr & & Content $_{2}$ \\
\hline Primary Sign: & Denotation & Expression $_{1}$ & Content $_{1}$ & \\
\hline
\end{tabular}

Metasemiotics

\begin{tabular}{|c|c|c|c|c|}
\hline Secondary Sign: & Metasemiotics & Expression $_{2}$ & \multicolumn{2}{|c|}{ Content $_{2}$} \\
\hline Primary Sign: & Semiotics & & Expression $_{1}$ & Content $_{1}$ \\
\hline
\end{tabular}

Figure 1. Connotation and metasemiotics. 
This theme, difference, means that meaning arises from differences in signifying practices. As difference requires relation, a single party would not be able to turn out meanings as supposed by the cultural authority model.

Neo-structuralists agree that structural differences are fluid and dynamic. Structure is far from being universal, as meanings depend on available resources (e.g. sign systems, discourses, interpreted meanings) and how these resources are combined. In general, neostructuralists show the limits of the assumption of universal structure, showing in process, how this assumption can undermine the original strive to discover meaning as difference. In particular, Barthes $(1967,1974)$ challenges the Levy-Straussian idea of reducing all myths into a single common structure. The idea, as he puts it, is ironic in itself, as it strives to reduce the complex reality into a simple pattern and then reapply this pattern to create endless repetitions. Was this not desertion of the difference logic? In Mythologies, Barthes (1972) argues that myths have a different function to that assumed by Levy-Strauss. He posits that myths, instead of resolving deep underlying oppositions between universal signifieds (e.g. nature versus culture), simply natural-ize historical values and habits. The conditionality of structure is also implied by Foucault (1975) in his Discipline and Punish where he considers the opposition (e.g. difference) between power and resistance. Power is more visible if it is accompanied with strong resistance. In the context of democracy, power is subtle, because resistance is mitigated via recruiting subjects into the voluntary re-creation of the very structure of the system. In the same vein, Derrida (1978b) deconstructs structure underscored by oppositions such as subjectivity versus objectivity or speech versus writing. He argues that these are not given but they represent signifiers the meaning of which arises in difference. In essence, Derrida accused the seminal structuralist writings (e.g. Saussure, Levy-Straus) of falling into the trap of logocentrism. Logocentrism seeks meaning outside structure, i.e. in the realm of pure consciousness (i.e. sense-making). Derrida (1978b) argued that meaning originates from differánce, the process through which signifiers defer (i.e. remove) the signified. Derrida talks of co-presence: the traces of an opposite concept invading the signifier. In other words, the sameself has the trace of the other and the other contains the trace of the selfsame. Thus, Derrida suggests re-conceptualizing the meaning of meaning: meaning is structure (e.g. differánce) rather than sense.

Lacan (2002) re-read Freudian psychoanalysis in the light of structuralist contributions. He argued that an agent becomes a signifying subject (i.e. yields agency) when he/she becomes a part of symbolic order while learning how to signify. Moreover, the holism of an organic self (i.e. the pre-linguistic being) is lost because language has limits - it cannot signify everything. The gap between a signifying subject and the organic self, which is not fixed but quite dynamic, engenders desire. Desire underlies the perpetual condition of dissatisfaction and the search for "something" that makes the agent whole again. This explains why people are drawn into the symbolic order even though they might realize in the process that this was not what they were looking for.

Recall the everyday situation in which my partner wants me to make a deal with him: "Please, I really love you, if we come together here, I will be totally dedicated to you! But if you reject me, I may lose my control and make your life a misery!" The catch here, of course, is that I am not simply confronted with a clear choice: the second part of this message undermines the first part - somebody who is ready to ruin me if I say no to him cannot really love me and be dedicated to my happiness, as he claims in the first part. The reality of the choice offered to me thus belies its terms: hatred or, at least, cold manipulative indifference towards me underlies both terms of the choice. 
There is, of course, a symmetrical hypocrisy, which consists in saying: "I love you and will accept whatever your choice will be; so even if (you know that) your refusal will ruin me, please choose what you really want, and do not take into consideration how it will affect me!" The manipulative falsity of this offer, of course, resides in the way it uses its "honest" insistence that I can say no as an additional pressure on me to say yes: "How can you refuse me, when I love you so totally?" (Žižek 2007, 14-15).

Here, Žižek (2007) explains Lacanian psychoanalysis in the context of a basic dyadic relationship. The quote illustrates the power of language (i.e. signification) in constructing structured social reality. An individual entering a common social space must pay the price: he/she is shrewdly coerced to act in a way it is expected from $\mathrm{him} / \mathrm{her}$ if the relationship is to be maintained. The agency, supposedly rational, free, independent, of the participant dissolves in the self that becomes the slave of symbolic order. It needs to maintain the social link unless it is deemed so insignificant to be absolutely forfeited through refusal. Walking away from the relationship would not free a person: had this happened the discourse would transform to a qualitatively different but similarly authoritative one. As Žižek (2007) explains, commitment to the relationship is a Trojan horse, a gift, which if accepted engulfs and controls a person. It appears to offer choice without granting the right to choose; it is there but cannot be grasped; it controls but is not susceptible to control. Interaction (in the form of symbolic order) between agents is above the agents, while the agents have no control over it.

Having explored these perspectives, we next apply structuralist and neo-structuralist ideas to explore how meanings are created in the context of green-marketing practices.

\section{Method}

We trace structure, i.e. patterns of signifying practices, evident in language used in corporate environmental reports and consumer discourses. Especially, the Internet has transformed meaning-creation practice by introducing a new environment where signification is intensive. Researchers argue that computer-mediated environments allow the unobtrusive observation of signification process (Kozinets 1999; Muñiz and O'Guinn 2001). Following the (neo)structuralist tradition, we believe that discourses in the form of text, inscribed by market participants themselves, express structure better than studies where a researcher, through participation, creates another specific "study" context in which signification might divert from its original path.

In particular, understanding how cultural meanings are constructed is important when a product or service under focus is a radical innovation. Hybrid cars are one such product category that are new to both of the exchangers in the market - seller and buyer (Srinivasan et al. 2009). In this article, our focus is not on the narrow context of product exchange signification. The focus is on a hybrid car brandscape the meanings of consumption and production practices constructed as the result of a pioneering technology entering the reference field of market participants. This event is taken as a change in the chaotic environment that needs to be interpreted. From a cultural perspective, the process of cultural meaning-creation in this context resembles an acculturation process. Acculturation consists in "intercultural interaction and adaptation and includes assimilation of a new culture, maintenance of the old culture, and resistance to both new and old cultures" (Pẽnaloza and Gilly 1999, 84). Hence, acculturation studies mainly study the impact of ethnic cultures. In contrast, we here focus on innovation acculturation, the ways through which market participants adapt to each others' 
newly created interpretive and physical practices enabled by innovations. We believe that in such new cultural contexts, to some extent, not only new practices, meanings, and identities need to be reflectively constructed, but also shared and learned.

Corporation and consumer discourses were observed from October 2005 to March 2009. During this period, we observed a number of online sources and downloaded relevant content text. We retrieved consumer communication from online forums and weblog sections of several Internet website dungeons: hybridcars.com, priuschat.com, greenhybrid.com, autoblog.com, and greencarcongress.com. The total volume of downloaded text from the consumer discourse domains amounted to 3173 pages of single-spaced, 10-point font which represents 7387 postings containing 1317 distinct user names and e-mail addresses. On the other hand, we acquired environmental and social reports published by automobile manufacturers. The sample included major car manufacturing corporations: Toyota Motor Corporation, Honda Motor Corporation, Ford Motor Company, and General Motors (GMs) Corporation. The volume of downloaded text from the corporate marketer domain amounted to 946 pages of singlespaced, 10-point font. This comprises 209 pages from Ford, 299 pages from GM, 237 pages from Honda, and 186 pages from Toyota affiliated sources.

The interpretive objective was to develop a body of in-depth neostructuralist interpretation that is relevant to this particular set of purposefully selected cases. The representativeness of a general population is not pursued in this study (Kozinets 2002). We used the qualitative data analysis software QSR NVivo 2.0 to organize and store documents in a text format, to code text chunks, and to create possible interpretive models. The process of interpretation involved several distinctive activities which were mostly coordinated simultaneously rather than being conducted in a linear fashion. Nevertheless, we conditionally call them stages. The first stage of the interpretive process involved organizing, arranging in a logical order, and then transforming all downloaded documents into a standard text format that allowed creating text codes within the NVivo's framework. In the next stage, the content from the two domains (corporations and consumers) was read and coded by one of the researchers. Depending on a discourse context, a code comprised a single word, combination of words, or whole paragraphs. For example, a big variety of substances considered (coded) as "emission" were identified. This code represented the corporate practices of recording, distinguishing, and categorizing different emission types. Another code "emission recycling" comprised, for instance, such corporate steps as transforming production fumes to fuel (Ford Corporation) or the use of the closed system of waste water circulation (Honda Corporation).

The researchers met regularly to review the codes and coded text across the documents using printouts from NVivo. They discussed them and made appropriate modifications. This process, that we conditionally call the third stage, was accompanied with continuous reflective writing to explain codes and their relationships. For example, "emission," "emission recycling," and other similar codes such as "emission control as safety enhancement" or "emission reduction as efficiency" are all related as these pertain to emission reduction management in a corporation. Moreover, hierarchical relationships were also explored. For instance, the code "the self correction" included the activities of emission reduction management which in turn comprised the code "emission." Exploring similar relationships helped us to arrange the codes into bigger themes that were also given unique codes. For instance, we detected the way corporations differentiate the self from the external environment. The self-attribute "emission reduction" was almost always contrasted to the external "emission output." Similarly, self-correction made sense of in the background of general "inaction" or 
"green self" was juxtaposed against "non-green others." These unifying codes were arranged into possible groupings and several interpretive models have emerged. Through several iterations of linking the model to the original text and modifications the final model has been constructed.

The interpretive method we used to derive themes is a critical approach that combines the structuralist (Levy 1981; Stern 1995) and deconstructive analyses (Stern 1997). The way we combined these virtually irreconcilable approaches is quite unique. The codes described above were grouped into common themes which were treated as binaries in the structuralist sense (Levy 1981). The strategy was to search for more codes that represent the opposite meaning of a particular theme. Consistent with structuralism, we identify oppositions and create hierarchies of meaning. But we do not make an attempt at reconciling oppositions (Stern 1997). Rather, using Hjelmslev/Barthes boxes, we show how meanings as binaries are interrelated at different "gestalt" levels. The second phase of our interpretive analysis is deconstruction (Stern 1997). We deconstructed oppositions by showing (a) limits of meaning; (b) contingency, instability of meanings; (c) impossibility of singular meanings; and (d) omissions and gaps in meaning-creation.

\section{Neo-structuralist analysis of greening practices}

\section{Green meanings created by corporations}

The analysis suggests that the corporate reports and their other communications generally function to natural-ize green practice (Barthes 1972). The argument, often iterated across the documents, rests upon the claims that green practice has long been a normal corporate focus: it is how things are naturally done since the very start of business operations. In addition, the corporations signify hybrid car technology as the direct consequence of their long-term - historically established - natural emphasis on greening. So, what signifiers are used to reference greening? Here, the process of signification is not uncomplicated.

Ordered through the adapted version of Hjelmslev/Barthes boxes, Figure 2 shows the general process of signification. Our original contribution is the incorporation of the forum of opposite meanings that are linked to the levels of connotation. It can be

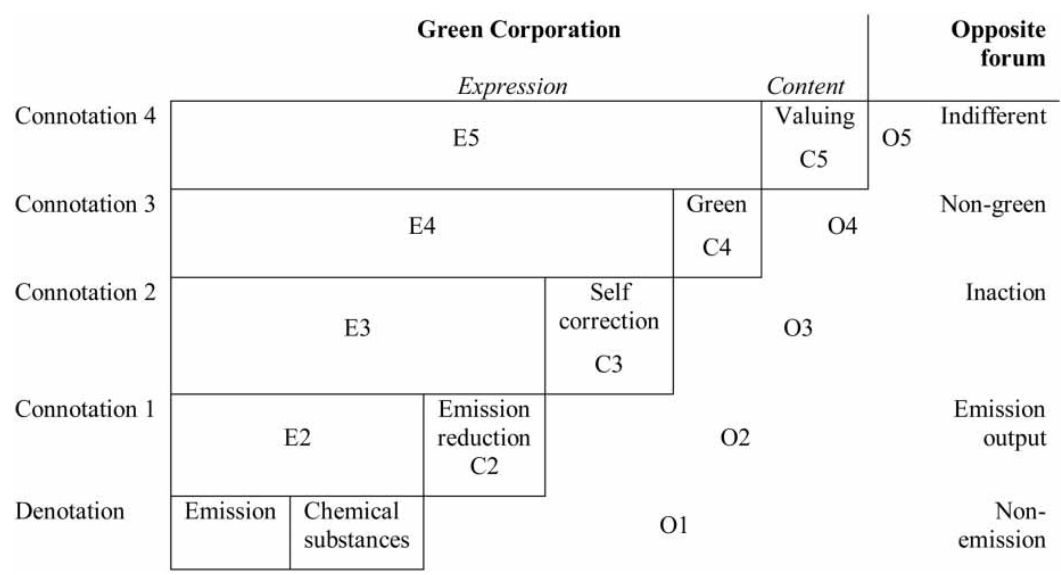

Figure 2. Constructing "green" in the corporate discourse. 
seen that the notion "Green Corporation" cannot be given meaning without referring to the opposite forum of meanings. In the documents, Green Corporation is constructed as the complex (highest-level) expression that unites multiple expressions and contents. In the figure, the higher levels of expression are coded as E2, E3 ..., whereas the higher levels of content are coded as C2, C3 ... As one goes up the levels, the new levels of content are created based on expressions with increasing complexity. At the same time, new content references its opposite. The binary opposition to the signified content is shown via $\mathrm{O} 1, \mathrm{O} 2 \ldots$ Generally, the figure can be explained either top-down or bottom-up. We will take the latter path.

In the most basic level that is labelled as denotation, the signifier "emission" denotes observed chemical substances: greenhouse gases (nitrogen oxide, methane, carbon dioxide, carbon monoxide, and hydrocarbons), CFC-12, sulphur dioxide, the substances of concern (SOC) (lead, mercury, cadmium, and hexavalent chromium), volatile organic compounds (VOCs), and industrial oils. However, this signifying defers (note that this process is coded as $\mathrm{O} 1$ ), other chemical compounds are considered non-emission as there seems to be some uncertainty with regard to their effect on the environment. For now, in this context, for example, replacing paint solvents containing VOC with new formula solvents (that might contain other chemical compounds) is considered to be the "success" of green innovation. That's how new (i.e. non-emission) substances assume positive meaning simply due to uncertainty of their impact on the environment. In this, emission is not only difference but also differánce (after Derrida) that defers the absolute meaning of possible types of emission.

Kjellberg (2008) notes that identity is built through the aggregation of actants (e.g. specific micro-practices). The signifier emission is related to chemical substances via such micro-practices. The corporations prevent, detect, monitor, control, isolate, and reuse emission. In general, the unity between the signifier and actants (coded E2) are understood as emission reduction (C2). This makes the first level of connotation. In this connotative context, emission reduction is not a simple content: it encompasses processes of observing, mapping, managing, and acting in a way that reduces the supposed damaging effect of business operations on the environment. Emission reduction refers to such diverse management practices as categorising emission (e.g. Toyota identifies a whole range of SOC that include lead, mercury, cadmium, and hexavalent chromium); isolating, reusing, and recycling emission (Ford recycles plant fumes to convert them into usable fuel); the use of emission to increase efficiency (Honda uses cogeneration systems); emission control to enhance general work safety (Toyota has improved emission detection systems); emission-related innovation (Honda came up with SOC-free bolts); emission control as local impact management (Honda and Toyota monitor soil and water quality in localities).

The fact that uncontrolled activities cause significant ecological damage needs to be established. In doing this, the corporation brings to attention its own awareness of common societal anxiety about harmful practices that exist within the industry. The reports discuss the industry's total effect on the environment and society. The industry's "environmental footprint" (Hart and Milstein 1999) is portrayed as given, natural. For instance, this passage from the environmental report gives an idea about the scope of the corporation's effect on the environment:

A total of 1.67 million tons of raw materials and supplementary materials, $34.5^{\prime} 10^{6} \mathrm{GJ}$ of energy in the form of electricity and fuel, etc., and 14.3 million cubic meters of water, were used at Toyota. 1.54 million tons- $\mathrm{CO}_{2}$ of greenhouse gases and 11.84 million 
cubic meters of water were released into the atmosphere and waterways respectively. Of 546,000 tons of the total volume of waste generated and not processed by Toyota, 540,000 tons was reused as recyclable resources in the form of raw material for steel, and 6,000 tons was disposed of in landfills. In logistics, $\mathrm{CO}_{2}$ emissions during the transport of 3.5 billion ton-kilometers of completely built units and parts amounted to 285,000 tons- $\mathrm{CO}_{2}$ (Toyota Motor Corporation 2005, 30).

In the recent report, Ford Motor Company recounts: "as a major multinational enterprise, we recognize that our activities have far reaching impacts on environmental, social and economic systems" (Ford Motor Company 2007, 156). The same report also tells that a Taurus-like family sedan weighing around 1.5 tons produces 60,000 $\mathrm{kg}$ of $\mathrm{CO}^{2}$ on average during its life cycle. Such anecdotal facts have a function: they consolidate and at the same time refer to the binary opposition. They suggest that the case of emission output is business as usual. This implies that all corporations face this "universal" fact, and only a few corporations (supposedly green ones) react. Here, emission reduction is implicitly compared $(\mathrm{O} 2)$ to emission output.

Hence, the natural and logical reaction of the observing corporation is nothing but cutting emission. In turn, the totality of these processes (E3) signifies a new content, self-correction (C3). At this level, emission reduction means that the corporation is doing at least something that is in its capacity to deal with environmental (ecological) problems perpetuated by the industry in general or the corporation in particular. According to the managerial signification, the green corporation is aware of and/or doing something about its own effect on the environment and society's natural resources. Hence, it is self-correction. This signifier is embellished with the claims of success. For example, the corporations register self-correction as the act of $\mathrm{CO}^{2}$ reduction within a certain period of time:

$\ldots \mathrm{CO}_{2}$ emissions decreased by 29,000 tons in financial year 2004, achieving the reduction goal" (Toyota Motor Corporation 2005, 36) or " $\mathrm{CO}_{2}$ emissions attributed to energy use in the production domain came to $467,600 \mathrm{CO}_{2}$-tons in fiscal 2004, up $5.1 \%$ from the previous year's level $445,000 \mathrm{CO}_{2}$-tons (a $24.0 \%$ reduction over the fiscal 1990 level). $\mathrm{CO}_{2}$ emissions were thus reduced by $2.8 \%$ compared with the numerical target of 481,000 tons (Honda Motor Company LTD 2005, 35)

Following the logic, the characteristic of a polluter emerges (O3): self-correction versus inaction differentiates the responsible company from the polluter. Therefore, the "proof" that the corporation is doing something about the problem is important. This establishes the next level of connotation. This is taken to be the distinction between green and non-green practice. Here, green practice (C4) signifies self-correction that is observed and reported (E4). For example, GM claims that the company “. . . is both reducing and reporting its greenhouse gas footprint through its globally integrated energy and carbon management strategy - a strategy that is measurable and verifiable" (General Motors Corporation 2007, 3-6). In this example, we note that GM has implicitly divided itself into two: the observing corporation and the observed one. The observing identity references the observed green identity in opposition to non-green corporations $(\mathrm{O} 4)$. If we accept the fact that observed self-correction is green practice, then the corporations which fail to self-correct, and moreover, to observe such self-correction cannot be labelled as green and responsible. This is the next level of connotation we term valuing (C5).

Corporate strategists attempt to create a societal position for the corporation as Green Corporation via valuing. Organizations dubbed (O5) as indifferent (i.e. those that do not engage in valuing) simply serve as the alternative forum of meanings. 
For the green corporation, other corporations are not green simply because they are indifferent to signifying their own acts within this particular meaning domain. In Lacan's (2002) terms, they are neither recruited nor engaged in this particular symbolic order. For example, a range of national automobile manufacturers in emerging economies such as Russia, China, Brazil, and Malaysia might not be as proactive as the global corporations we observe in signifying green practice. The difference between valuing and indifference symbolizes the pattern through which the meaning of becoming "green" is fixed in implicit differentiation.

Figure 2 represents the general structure of the signification process. However, such structure is not universal and less so natural and fixed. Rather it simply naturalizes the fiction that green practice is natural. In naturalizing the fiction, the structure becomes flexible, often imperfect, and an ongoing project of building a green corporate identity. Also, it is inherently paradoxical. To create intended meaning, corporate stakeholders should accept the fact of industrial unsustainability to be substantial. The bigger the extent and scope of the problem the more rational is self-correction. The practice of self-correction is not likely to diminish in importance as long as the problem is maintained (constructed) as formidable. Therefore, we note that Green Corporation signifies the ecological problem rather than the absence of the problem. On the other hand, selfcorrection cannot be sustained indefinitely. In the context of emission reduction, the rates suggested cannot be possibly maintained infinitely unless more emission in absolute terms is generated. An emission reduction goal, for instance, 24\% a year, is indeed not sustainable. This means that cutting emissions and generating them should go handin-hand. This also means that the greenness of the corporation, i.e. the meaningfulness of its "green" image, is not sustainable. Furthermore, denotation of a particular actant as green (more specifically, emission reduction) depends on a metasemiotic switch. For example, the actant such as monitoring industrial oil leakage from pipes in manufacturing facilities can be connoted differently in different metasemiotic contexts (Figure 3).

In the context of efficient operation, the actant signifies daily routine to prevent inefficiency, and consequently, saving costs. But within the green discourse, it is interpreted as care for soil resources. The observed switch from one metasemiotic to another changes connotation and also, changes the nature of a binary opposite. Most probably, the sign has not changed but its meaning has transformed from being the opposite of inefficiency to the opposite of apathy towards the environment (soil). What is interesting is that it is the "right" signification, not a natural fact that creates the green identity.

\begin{tabular}{|c|c|c|c|c|c|c|}
\hline \multicolumn{5}{|c|}{ Green (efficient) corporation } & & \multirow{2}{*}{$\begin{array}{l}\begin{array}{r}\text { Opposite } \\
\text { forum }\end{array} \\
\text { Indifference } \\
\text { to soil }\end{array}$} \\
\hline Metasemiotic 2 & Green & $\begin{array}{r}\text { Monitori } \\
\text { oil } 1\end{array}$ & $\begin{array}{l}\text { industrial } \\
\text { kage }\end{array}$ & $\begin{array}{c}\text { Care for } \\
\text { soil }\end{array}$ & $\mathrm{O} 3$ & \\
\hline Metasemiotic 1 & $\begin{array}{l}\text { Operational } \\
\text { efficiency }\end{array}$ & $\begin{array}{r}\text { Monitori } \\
\text { oil } 1\end{array}$ & $\begin{array}{l}\text { industrial } \\
\text { kage }\end{array}$ & $\begin{array}{c}\text { Cost } \\
\text { saving }\end{array}$ & $\mathrm{O} 2$ & $\begin{array}{l}\text { Inefficient } \\
\text { operation }\end{array}$ \\
\hline Denotation & & Emission & $\begin{array}{c}\text { Industrial } \\
\text { oil }\end{array}$ & & $\mathrm{O} 1$ & $\begin{array}{c}\text { Non- } \\
\text { emission }\end{array}$ \\
\hline
\end{tabular}

Figure 3. Metasemiotic switch. 


\section{Consumer meanings}

The beauty of these cars is that they "give you the tools" to modify your driving habits in order to best take advantage of the technology. If you are not interested in "playing the game" of trying to see how high you can keep your tanks on a consistent basis, then a hybrid is probably not for you. Anyone can slow down, take a different route, accelerate more slowly, and all that stuff, in ANY vehicle, and their MPG will improve. But in a hybrid, you have instruments you can use as tools to help guide you to discovering the best MPG under certain circumstances. And you can certainly drive the speed limit in a hybrid and get good MPG... The thing that TOO MANY people do is "zoom zoom zoom" from traffic light to traffic light, in a hurryhurryhurry-gottagetthere-fiveminutesago style, and that KILLS your MPG. I love my new Hybrid driving style, and I am still learning my car after almost 15 months (posted by 1s1, on 26/09/2005, at www.greenhybrid. com).

In online milieus, hybrid car consumers are seen to be reflecting on their own practice while sharing their experiences. It is maintained that the hybrid real driver must learn or discover "the correct" driving anew. Moreover, they should maintain persistent control over their own behaviour and over the car's condition. The importance of consistent self-regulation means that green consumption does not stop with a choice and purchase. Rather, consumer symbolic order pushes consumer beyond the limited realm of exchange towards playing the "correct" game.

In comparison to meanings created by the corporations, product users' meaning for green practice is no less paradoxical. Although the context and content of meaning-creation is totally different, the structure of meaning-creation bears certain resemblance (Figure 3). In contrast to the corporations, consumers do not attribute the origin of environmental problems to themselves. Rather they create the meaningful "green driver" identity by differentiating themselves from other drivers at different connotative contexts.

In our analysis, denotation that is shown in Figure 4 is manifested in consumers' reflection on driving practices. These practices encompass goals, principles, strategies, attitudes, style, and habits related to vehicle-driving. A range of new terms (signifiers) are created to signify these practices that are uniquely "hybrid." In other words,

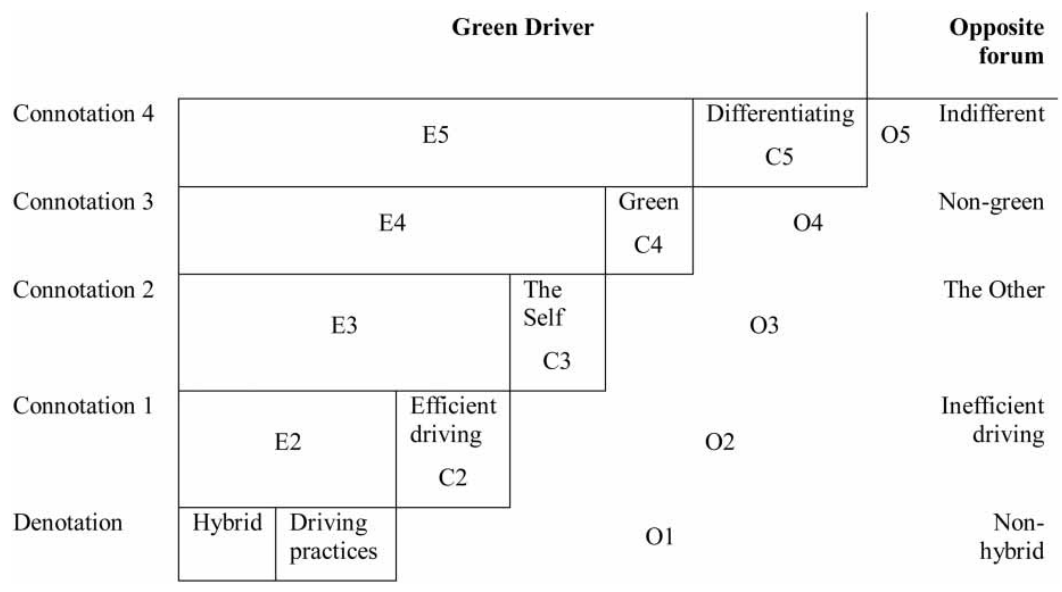

Figure 4. Signifying "green" in consumption discourses. 
differences emphasized by the new terms are given specific meaning within the symbolic order. For instance, the ultimate goal of a hybrid car driver is to maximize "latest tank MPG" or to "get an EPA number." In context, the latest tank miles-pergallon (MPG) signifies the measure of average fuel efficiency gauged in MPG achieved on the latest tank fill up. In a forum posting, another goal is emphasized:

If you drive a Hybrid "like a regular car" and DO NOT take any actions to try to maximize your MPG, you will not get EPA numbers ... (posted by 1s1, on 26/09/2005, at www. greenhybrid.com).

The extract draws attention to the goal of getting Environmental Protection Agency (EPA) numbers. The term signifies driving to achieve fuel-economy ratings certified by the US EPA. As fuel-economy readings in real-driving situations significantly lag behind over-optimistic EPA ratings, hybrid consumers accept them as personal driving goals. Furthermore, the principles of hybrid-driving include such accepted norms as less braking, smooth acceleration, slow driving, minimum travel weight as possible, and so on. Especially, the "7MPH" principle is propagated: a person decelerating should avoid speeds below seven miles-per-hour. Also, a number of hybrid car driving strategies exist. For instance, in the hybrid discourse, a traditionally simple act such as braking represents a complex driving strategy. Hybrid car enthusiasts' website HybridCars notes: "Native Alaskan people have many words for 'snow,' and Prius hypermilers have at least four words for how to brake" (HybridCars 2011). Accordingly, they go on to suggest that one can do gliding, coasting, regenerative braking, and mechanical braking.

It is not our purpose to document all types of practices labelled as hybrid-driving. We note that this is a denotative process that conceals reference to non-hybrid-driving (O1). In other words, hybrid-driving is contrasted to conventional driving styles. Any indifference towards hybrid-driving practices symbolizes this new forum of meaning. For example, hybrid car ownership is not a criterion of hybrid-driving. It is noted that many hybrid owners drive their hybrid cars in a non-hybrid way (i.e. conventional driving). Therefore, from the perspective of the whole signification process, one realizes that hybrid car ownership does not automatically qualify a person as a green driver. At the connotative (1) context, hybrid-driving practices (E2) represent efficient driving (C2). Such a signification is traced in commentaries on habits of conventional driving that foster inefficiency (O2). Non-hybrid vehicle drivers are often portrayed as inefficient drivers:

Enter my non-hybrid driving wife. She needed my [hybrid vehicle] in order to pick up a piece of furniture. I offered her the keys with pride - knowing that my [hybrid] got better mileage than her TSX and was able to haul a large dresser. When my [hybrid car] came back, the 38.7 MPG (miles per gallon) was sitting at 25.4 MPG. She put less than 30 miles on the odometer, but crushed my dream tank. I couldn't even bring myself to calculate how many MPGs she achieved with her inefficient driving style (Miller 2005, para 4).

In general, an assumption underlies self-reflection: we all were once inefficient drivers in the past and now we have got "enlightened." However, the consumers do not attribute inefficiency to themselves as the corporations do. They distance themselves from it by seeing the self, an efficient driver, in the light of the other (it can also be the self in the past). The hybrid car consumers construe and consolidate the self (C3) through activating comparisons to the consumers of other car categories, 
the other (O3). For example, the advantages and disadvantages of the hybrid car vis-àvis the (bio)diesel engine car is discussed:

\begin{abstract}
Which is better: 1) buy a diesel car: in the short term, you would be saving yourself some money (diesel isn't an expensive technology), improving your fuel economy, hurting the environment (just a little bit), and contributing to rising health care costs. In the long term, you'd be funding the research to switch to bio-diesel fuel, which is cleaner and possibly more fuel efficient. It might even bring about an improvement in piston engine design that increases horsepower and torque. The engine still needs motor oil though. 2) buy a hybrid car: in the short term, you'd be spending a couple thousand extra (vs. a gasoline or diesel powered car), improving your own fuel economy (comparable to a diesel engine), helping the environment a LOT, helping to reduce health care costs, and reducing not only dependence on foreign oil, but any fossil fuels. In the long term, you'd be helping to fund battery research, electric motor research, and fuel cell research. You're still using gasoline, you're still using motor oil, but half of the engine is using NEITHER motor oil NOR gasoline (posted by Tm1, on 28/02/2005, at www.hybridcars.com)
\end{abstract}

This excerpt shows that the meaning constructed involves depiction and interpretation of the other as part of the self. In this form of depiction, hybrid car practices emerge as being more environmentally friendly, more conducive to health improvement, more helpful to national foreign policy, and more supportive of superior fuelcell research. Hence, the observed self is green (C4). Sport utility vehicles (SUVs), (bio)diesel cars, electric vehicles, or fuel-cell vehicles become a point of reference for comparison. These "other" car categories and related practices are assessed from within the discourse. The hybrid car fans build their judgement in conformity with their internal logic rather than portraying objectivity in their assessment. For example, although SUVs are commonly assessed as powerful, spacious, and sporty by many non-hybrid drivers, the hybrid enthusiasts construct it as the "radical enemy" of the hybrid car, and thus, the sustainability cause. To them, the SUV is a gas-guzzler, the paragon of apathy to societal problems, and the symbol of waste and environmental destruction. Hence, the other is non-green (O4). Of course, this signification should certainly exclude the category of hybrid SUVs. In this, green is difference; not a natural characteristic of the self. A bit paradoxical ... c'est la vie!

At the level of signifying via written language, as it happens in online environments, another connotation is realized. The green driver is the subject of a specific connotative practice exhibited in differentiating between green and non-green in language (C5). Indifference to differentiating seen in hybrid car owners' refusal to participate in signification in general and online discourses in particular puts the person outside the domain, i.e. the symbolic order. Just like a Non-green Corporation that faces the fact of emission but fails to engage in valuing, Non-green Drivers are consumers who fail to observe their own practices according to accepted signifying principles. Often, the Green Driver identity becomes aggressive practice if taken a little further. In extreme cases observed, hybrid car fans ridicule the other in most unsuitable ways. They also tell stories of their own violent behaviour towards supposed "enemies" in traffic situations. They sometimes create conflicts by "bragging" about self-virtues, and even issue "green tickets" to gas-guzzlers. Green Driver identity turns into dogmatic fanaticism and within the symbolic-order boundaries such actions appear to be justifiable (Smith, Fisher, and cole 2007). Here, we should note that the consequences of fanaticism are the negative socio-cultural spill-over of meaning-creation. 


\section{Model of meaning co-creation}

Meanings constructed in the two discursive milieus are diverse, yet they seem to maintain similar structure. In other words, the signification processes are organized in more or less comparable ways. It is evident that the corporate marketers do not exactly define the meaning of "green" for consumers; neither do consumers do this for the marketers. Rather marketer meanings pre-suppose consumer meanings, and vice versa. In general, Derrida's differánce underlies creation of comparable meaning structures (Figure 5). Figure 5 implies that the identity Green Corporation maintains implicit reference to the Green Consumer identity, and vice versa. The reference is that of deferring. Green Corporation contains the trace of consumer meanings, because it functions as an appeal to consumer meanings via natural-izing greenness. At the same time, it not only defers Green Consumer but also conceals it within own discourse. Rather, the portrait of the typical hybrid car customer is that of a "rational decision-maker" who would not sacrifice functional performance for mere greenness.

Consistent with Caruana and Crane (2008), our analysis shows that the corporations implicitly appeal to rationality of their customers: greener corporations offer greener products while keeping quality intact which should appeal to the rational consumer. Whether to consume or not (for example, walking, taking public transport, riding bicycle) is not considered as an issue. Rational and responsible consumer is a myth communicated. Diverging from Caruana and Crane (2008), we argue that such myths are not directed at consumers but they are inward-looking as to function as a means of sense-making. Myths have the function of natural-izing, i.e. providing foundation for meaning construction. In the same way, Green Corporation is a deferred signified for consumers. They may even realize that hybrid car champions (e.g. Green Corporations) are also the producers of the most gas-guzzling models.

In particular, Figure 5 juxtaposes connotative meanings created by the both corporations and consumers. In the figure, the multilayered character of connotations is represented by the cascade of boxes placed within each other. At the highest connotative level, corporate valuing sets Green Corporation apart from non-green corporations, and at the same time, attracts consumers to the common field of signification. Consumers are involved in differentiating between green and non-green consumers which also recruits marketers to the field of symbolic order. Although there is no one-to-one

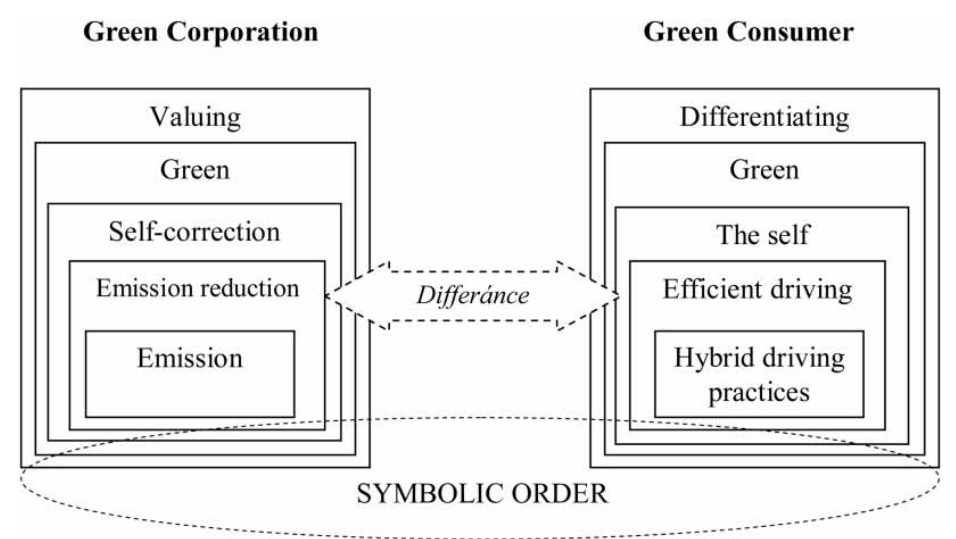

Figure 5. Model of meaning co-creation. 
meaning match, the solidarity between two groups is mainly aesthetic. For instance, taking self-correction as the signifier of green practice is not exactly the same as taking the self to be greener than the other, neither is identifying correct emissions the same as identifying correct hybrid-driving practice. Instead, here signification plays a role of invitation and recruitment. It is invitation to participate and co-construct meaning structures. Accepting the "invitation" means becoming entangled in this particular structure of meaning-creation. Moreover, this symbolic order is perpetually reproduced even though some meanings appear to be paradoxical.

We note that the observed "green" symbolic order is the result of aesthetic recruitment, at least in the context of our research. The similar term "aesthetic seduction" is suggested by Maturana and Varela $(1980,1992)$ to denote attraction to beauty - desirable and harmonious - which gives a person the sense of the real. Using Lacanian (2002) explanation, the real is something that makes a person whole again, i.e. returns him/her to a pre-signification condition. Alas, what the green identity does is to generate more signification. Aesthetically recruited agents have no choice but to emulate the structure. It is an interactive process. Hence, one should not look for the atomistic origin. Neither marketers nor consumers can claim authority to the structure that emerges as a whole. Furthermore, structure is malleable, fluid, and transformative. It may encourage commonalties but it is by no means universal.

\section{Discussion}

\section{Neo-structuralist explanation of behavioural inconsistency and inauthenticity}

Despite being aesthetically appealing, structure represented in the model of meaning co-creation is inherently paradoxical. Following the neo-structuralist notion of meaning being structural, we note that the meaning of "green" necessitates the consolidated forum of opposites. For a corporation, at the denotative level, it is translated in to a constant search for new sources of emission and ways of transforming "non-emission" to "emission." At the next level, a significant magnitude of emission output needs to be maintained (how else would they be able to claim increasing cuts in emission?). At the higher level, self-correction is preferred to inaction which is the same as saying that a remorseful offender (who in fact did not give up the offence but argues that it is natural) is better (e.g. greener) than others. Similarly, consumers are motivated to consolidate the opposition. More and more hypermiling practices are signified as hybrid-driving while the cases of inefficient driving are purposefully selected and targeted.

From the system participants' perspective, such structural meanings would seem natural, grounded, and fixed as they conceal the opposites. From the independent observers' perspective, they appear disjointed and contradictory. In this case, both parties become the subject of structure. Instead of independent, rational Cartesian ego, the Green identity has become nothing more than structure underlined by language and signification. Caruana and Crane (2008) offer a review of green-marketing research where the assumption of a sovereign green consumer is strongly maintained. According to the sovereign consumer thesis, consumers are "autonomous, powerful, rational agents" (Caruana and Crane 2008, 1497). Moreover, consumer responsibility (e.g. greenness) is an inherent "measurable quality possessed by individuals" (1497). In general, nonstructuralist research tends to attribute greenness or non-greenness to be the quality of system participants. In a similar sense, inauthenticity in actual consumption (or production) is attributed to "green" consumers and corporations when their observed 
practices are not consistent with their stated goals. This research shows that the symptoms of behavioural inconsistency are at the heart of structure. In other words, behavioural inconsistency, and thus, inauthenticity is structural. The system possesses this deficiency as the necessary element of reconstruction and reorganization.

\section{Interactively co-created structure}

The structuralist analyses in general and its application in consumer research focuses on the universal properties of structure (Levy 1981; Stern 1995). The structure of green practice that is explained in this research is neither universal nor fixed. It does not refer to stable relations or binary oppositions in Levy-Strauss's sense. The vision we have is of a dynamic order that is in constant flux depending on what oppositions are played out by parties in relation. Structure that underlies the content of meanings for the two groups is built in interaction. In this context, cultural transfer of meaning refers not to a simple transfer of structure but to the co-creation of meaning-making patterns. In other words, we do not claim that structure is transferred or copied directly. Moreover, structure does not flow one-way from marketers to consumers. Structure sharing is to be visualized to be cyclical rather than linear. Structural interaction conceptualized in this article is in agreement with the view of communication as a social process. This view eschews the dominant model of communication expressed in a conduit metaphor of message delivery (Axley 1984; Krippendorff 1993; Varey 2000). There seems to be no conduit-enabled transfer of meanings content, at least as far as the observed market participants are concerned.

\section{Meaning concepts and market culture}

Nöth (1990) refers to different meaning conceptualizations such as meaning-as-reference and meaning-as-sense. In Table 1, we contrast these two perspectives to the view of meaning-as-structure. Here, meaning-as-structure refers to the totality of meanings that arise as self- and market-understandings, i.e. action potentialities, within a symbolic order. The table shows that the understanding of market culture changes depending on which concept of meaning is emphasized.

In the meaning-as-reference perspective, meaning is associated with a real thing or a class of things that exist independently from the human mind. Meaning is taken to be an object that is referred to. In mainstream marketing, the "object signification" approach is dominant which has been extensively analysed and criticized by Holt (1997). This perspective posits that consumption objects are "vessels of meaning" and that they characterize the users of these objects (McCracken 1986, 2005). It is assumed that manufacturers create meaning by creating differentiated goods and services. Accordingly, the transfer of meaning happens in the process of market exchange where consumers "vote" for favourable attractive meanings through purchase. Differentiation whether relevant or irrelevant - creates meaning (Carpenter, Glazer, and Nakamoto 1994). The hybrid category of vehicles is differentiated based on a bundle of associated unique attributes. Unique attributes are equated to unique meanings, as producers profit from them while consumers exhibit corresponding demand. The assumption here, for example, could be that market participants embrace the hybrid car culture because they are involved in creating, promoting, exchanging, using, and disposing of this object. Further, we note that the cultural authority model would be deemed partially relevant if one is willing to take meaning as reference. Certainly, marketers are involved in 
Table 1. Different views of market culture according to the different meaning conceptualizations.

\begin{tabular}{|c|c|c|c|}
\hline $\begin{array}{l}\text { Meaning } \\
\text { conceptualizations }\end{array}$ & $\begin{array}{l}\text { Definitions of } \\
\text { meaning }\end{array}$ & Cultural transfer & $\begin{array}{l}\text { Conditions of } \\
\text { initiation to market } \\
\text { culture }\end{array}$ \\
\hline $\begin{array}{l}\text { Meaning-as- } \\
\text { reference }\end{array}$ & $\begin{array}{l}\text { Meaning refers to } \\
\text { an object }\end{array}$ & $\begin{array}{l}\text { Object signification } \\
\text { approach: objects are } \\
\text { created and change of } \\
\text { ownership is } \\
\text { encouraged; object } \\
\text { consumption patterns } \\
\text { define prioritized } \\
\text { meanings in markets }\end{array}$ & $\begin{array}{l}\text { Market agents create, } \\
\text { exchange, use, } \\
\text { dispose of products } \\
\text { and services }\end{array}$ \\
\hline \multirow[t]{2}{*}{$\begin{array}{l}\text { Meaning-as-sense } \\
\quad \text { (consciousness) }\end{array}$} & $\begin{array}{l}\text { Meaning refers to a } \\
\text { mental event }\end{array}$ & $\begin{array}{l}\text { Cultural authority } \\
\text { model: marketers } \\
\text { create and dictate } \\
\text { commodified } \\
\text { meanings; consumers } \\
\text { either passively accept } \\
\text { or reflectively and } \\
\text { creatively resist } \\
\text { marketer meanings }\end{array}$ & $\begin{array}{l}\text { Market agents create } \\
\text { and modify } \\
\text { commodified } \\
\text { meanings }\end{array}$ \\
\hline & & $\begin{array}{l}\text { Postmodern branding: } \\
\text { marketers borrow } \\
\text { meanings from } \\
\text { popular culture and } \\
\text { feed them back to } \\
\text { consumers }\end{array}$ & $\begin{array}{l}\text { Market agents work } \\
\text { with an array of } \\
\text { meanings to use } \\
\text { them as resources } \\
\text { for identity } \\
\text { construction }\end{array}$ \\
\hline $\begin{array}{l}\text { Meaning-as-sense } \\
\text { (idealism) }\end{array}$ & $\begin{array}{l}\text { Meaning refers to } \\
\text { the Platonic idea } \\
\text { that is } \\
\text { independent of } \\
\text { users and signs }\end{array}$ & $\begin{array}{l}\text { Market ideology: market } \\
\text { ideals (myths) } \\
\text { sustained by } \\
\text { marketers are pursued } \\
\text { by consumers }\end{array}$ & $\begin{array}{l}\text { Market agents sustain } \\
\text { and pursue market } \\
\text { ideals }\end{array}$ \\
\hline $\begin{array}{l}\text { Meaning-as- } \\
\text { structure }\end{array}$ & $\begin{array}{l}\text { Meaning refers to } \\
\text { structure }\end{array}$ & $\begin{array}{l}\text { Aesthetic recruitment: } \\
\text { subjects are attracted } \\
\text { to symbolic order and } \\
\text { start reproducing } \\
\text { structural meanings }\end{array}$ & $\begin{array}{l}\text { Market agents accept } \\
\text { and participate in } \\
\text { symbolic order }\end{array}$ \\
\hline
\end{tabular}

creating differentiated attributes. However, marketers might greatly rely on market research that taps into consumer insights unless the pure product concept is pursued. Therefore, marketers cannot (would not) claim full authority as it contradicts the very conception of orthodox marketing.

In contrast to reference, meaning-as-sense consists in locating meaning outside material objects. One form of this is the assumption that meanings reside in mind. Since meaning is taken to be a mental event, it is associated with images that arise in individuals' cognition. Ringberg and Reihlen (2008) propose a socio-cognitive model that is based on the assumption that meaning construction is mediated through mental models. As they argue, mental models are used to meaningfully internalize environmental events. Similarly, as Holt (2002) indicates, the cultural authority model is based on the assumption that marketers are the engineers of commodified 
meanings. Consumers, in turn, either act passively to accept suggested meanings or act actively to reflexively resist or modify these meanings. Furthermore, Holt (2002) argued the cultural authority conjecture has become irrelevant in modernity. More and more firms in fact borrow existing popular cultural meanings and feed them back to consumers. From this perspective, the meaning of the hybrid car is not its different attributes but the battery of diverse meanings which marketers, consumers, enthusiasts, and public imbue it with. For example, the hybrid car stands as the symbol for naturalized corporate greenness for marketers.

Another form of meaning-as-sense, idealism, maintains that Platonic ideals are sustained by marketers through story-telling, emotional branding, and myth creation, while consumers strive to attain these ideals through consumption (Holt and Thompson 2004; Thompson, Rindfleisch, and Arsel 2006). The Platonic ideal depicts a universal value that is independent from (above) the reality we experience. For example, there are no perfect green/sustainable products or meanings in this world. The only thing that is real is the Idea of Sustainability, the state of being truly impactless for infinite generations. Toyota links Toyota Prius, the leading hybrid car brand, to the ideal of sustainability. The ideals are universal and are not susceptible to manipulation. Moreover, consumers are found using marketer-created stories and myths as resources for further meaningcreation and modification (Holt and Thompson 2004; Thompson, Rindfleisch, and Arsel. 2006).

In this article, we show that cultural meanings are formed via the common structure which is reproduced through idiosyncratic marketing and consuming practices. The culture springs from the aesthetic recruitment of individuals to a common cultural space. This common space enables meaning-making via differánce. In contrast to other perspectives, we note that culture here represents neither physical products (goods or services) nor commodified and popular meanings nor myths and ideals. It represents a symbolic order that is co-created. It is neither engineered by marketers nor made available by consumers and related publics. The acceptance of the symbolic order means commitment on the part of the market agents to follow the structured path of meaning-creation. At least in the context of hybrid car production and consumption, the cultural authority assumptions do not hold because meaning as structure is impossible to manipulate.

\section{Structural silence}

An important and somewhat paradoxical trend observed is that green-marketing practices and discourses intensify rather than suppress potentially eco-harmful production and consumption in the absolute (volume of throughput) sense (Welford 1997; Smith 1998; Crane 2000; Connolly and Prothero 2003; Caruana and Crane 2008). Researchers wonder about why the following essential issues are generally silenced or absent from the green-marketing discourse: (a) no consumption (production); (b) less consumption (production); (c) alternative zero-impact consumption (production). From the meaning-as-structure perspective, the ultimate question of whether to consume or not (Connolly and Prothero 2003; Caruana and Crane 2008) boils down to whether to embrace the symbolic order of green practice or abandon it. Is commitment necessary? Lacan (2002) argued that one does not have a choice. People are born into the reality structured by signification. In modern (industrialized) societies, forgoing a symbolic project results in lost sense, meaninglessness, alienation, social psychosis, and the last but not the least, shattered hope to return to the holistic condition (Lacan 
2002). Specifically, environmentalism is at the heart of living social lives (Dolan 2002). Therefore, the signification of green practice is unavoidable whether we want to confirm or deny it.

On the other hand, we note that by silencing essential choices for action, the signification process of green-marketing becomes a malice on its own against that which it is fighting (refer to Zižek 2007). In fact, it suppresses rather than fosters creativity in greening practices. Regarding individual market agents, is authenticity relevant as discussed by Holt (2002)? Is authenticity or hypocrisy no longer possible in green-marketing? We note that market agents can still choose to behave authentically or hypocritically depending on their real intention. However, because of the ordered signification path which they are forced to follow, it does not really matter whether they are authentic or insincere in engaging in green practice. The resulting meanings would still be the same. Recruited into the symbolic order, they would end up silencing the potential choices of transformative and radical changes (Varey 2010).

\section{Conclusions}

This investigation shows that corporations and consumers become the subjects of common symbolic order just like Žižek's (2007) subjects of relationship. By committing themselves to the structural way of meaning-creation, they are forced to perpetually reproduce inconsistent behaviour. This is the cost they should pay for the privilege to search for "the real" (Lacan 2002). If Barthes's (1972) analysis indicated the death of the author, our analysis alludes to the death of cultural authority (Holt 1997). Holt (2002) critiqued the model from the meaning-as-sense perspective. His premise was that the model is irrelevant because marketers borrow rather than engineer meanings. Taking the meaning-as-structure perspective, we show that culture that arises as the symbolic order is context-specific and interactively created. The corporations are not able to claim authority to structure: it is co-created rather than determined. The notion of aesthetic recruitment posits that culture is created in the process of structural meaning co-creation. The problem is that the higher levels of connotation are not only free of signifieds but also require contradictory action. Structure necessitates valuing in order to give birth to the Green Corporation, in other words, managers become very adept at signifying greening practices but fail to act in coherent manner (Smith 1998; Varey 2010). Similarly, consumers are attracted to the very structure. They become very adept at differentiating between green and non-green yet fail to act coherently. The important question is who is to be blamed for the problematic practice?

The paradox has led many critics to label the corporation/consumer meaning-creation as inauthentic. Our model indicates that the green practice is neither greenwashing nor hypocrisy. It simply is necessity (i.e. a building block) for meaning co-creation. We note that a particular unsustainable condition (e.g. ever-increasing emissions for the green corporation, negative fanaticism for the green driver) must be maintained or reified by the subjects. This way it entails a commitment to the unsustainable action as the basis for constructing the green self. To summarize, the Green Corporation would not exist without greenwashing, whereas Green Consumer would not operate without hypocrisy. This simply is the price to be paid for meaningfulness. Put in another way, the paradox is the side-effect of the co-created structure. If the paradox is observed in corporate practices, then the observers must understand it as a structural problem which is shared by all of the society members including the critics themselves. If the paradox is found in consumers' practice, its traces will be found in all other 
societal systems. If inauthenticity is a problem, then it pertains to neither corporations nor consumers. It is the disease of a whole market system that draws its vitality from signification processes.

\section{Limitations and further research}

This investigation is a first step towards exploring the role and importance of the symbolic order for meaning-making practices in consumption markets. As it can be expected with unorthodox approaches, the current analysis of meanings in green-marketing is not without limitations. The notion of the symbolic order and its relevance for constituting market/consumption agents and relations needs to be examined further. Specifically, a thorough understanding is required of processes of how the symbolic order both enables and limits meaning-creation as operant in the self- and marketunderstanding.

Moreover, sustained research on how inauthenticity and behavioural inconsistency operates at the basis of green practice, and possibly, as the foundation of similar consumption and production practices in general, is needed. It appears that inauthenticity rather than authenticity is the driving force in market practices. Apart from this suggestion being as controversial as it sounds, we realize that our research is greatly contextualized and can only be safely claimed to be relevant within a specific market discourse. Factors, condition, and circumstances that necessitate inauthenticity might well be different in different meaning settings and milieus. We call for more research to explore the extent to which this phenomenon is relevant to other meaning-making practices.

Furthermore, differences among the suggested broader perspectives of meaning (e.g. meaning-as-reference, meaning-as-sense, and meaning-as-structure) should be better investigated. The current investigation is unable to do justice to it in terms of dedicating more time and effort to refine the framework and draw implications for cultural studies. Further research is needed that takes the framework as a starting point of analysis and carries out systematic application of the framework to elaborate on the fundamental issues of markets and cultures.

We recognize that the sample we use is simply a small part of the content generated daily in many other different contexts via different media. Not only corporations and consumers, but also other publics participate in building the symbolic order. Therefore, further research is needed to investigate signification practices of different stakeholders in both virtual and non-virtual environments.

\section{Note}

1. We prefer the notion of neo-structuralism to the term poststructuralism. There are several reasons. First, these writings do not make a unified body of theory (Holt 1997); rather, umbrella terms (e.g. poststructuralism, neo-structuralism, postmodernism) are used to delimit diverse and often contradicting perspectives (Frank 1989; Nöth 1990; Belsey 2002). Structuralist ideas are not only the foundation or a starting point for these analyses of culture, but also the source of inspiration. Derrida (1978a) did not consider himself apoststructuralist, arguing that his analysis was both structuralist and anti-structuralist which in general focuses on structural problematic concepts. Nöth (1990) considered the writings of the aforementioned authors to be the part of the structuralist philosophy. He argued that structuralist concepts are so ingrained in their writings that the right term to use would be neo-structuralism or super-structuralism. This view is supported by other reviewers too (Frank 1989). 


\section{References}

Arnould, Eric J., and Craig J. Thompson. 2005. Consumer culture theory (CCT): Twenty years of research. Journal of Consumer Research 31, no. 4: 868-82.

Axley, Stephen R. 1984. Managerial and organizational communication in terms of the conduit metaphor. Academy of Management Review 9, no. 1: 428-37.

Barthes, Roland. 1967. Elements of semiology. London: Cape.

—. 1972. Mythologies. London: Paladin.

- 1974. S/Z. Paris: Farrar, Straus \& Giroux.

Belsey, Catherine. 2002. Poststructuralism: A very short introduction. Oxford: Oxford University Press.

Carpenter, Gregory S., Rashi Glazer, and Kent Nakamoto. 1994. Meaningful brands from meaningless differentiation: The dependence on irrelevant attributes. Journal of Marketing Research 31, no. 3: 339-50.

Carrigan, Marylyn, and Ahmad Attalla. 2001. The myth of the ethical consumer - do ethics matter in purchase behaviour? Journal of Consumer Marketing 18, no. 7: 560-78.

Caruana, Robert, and Andrew Crane. 2008. Constructing consumer responsibility: Exploring the role of corporate communications. Organization Studies 29, no. 12: 1495-519.

Connolly, John, and Andrea Prothero. 2003. Sustainable consumption: Consumption, consumers, and the commodity discourse. Consumption Markets \& Culture 6, no. 4: 275-91.

Crane, Andrew. 2000. Marketing and the natural environment: What role for morality? Journal of Macromarketing 20, no. 2: 144-55.

Derrida, Jacques. 1978a. Writing and difference. London: Routledge.

—. 1978b. Of grammatology. Baltimore: John Hopkins University Press.

Dolan, Paddy. 2002. The sustainability of "sustainable consumption." Journal of Macromarketing 22, no. 2: 170-81.

Ford Motor Company. 2007. Ford Motor Company sustainability report 2006/2007. Dearborn, MI: Ford Motor Company.

Foucault, Michel. 1975. Discipline and punish: The birth of the prison. New York: Random House.

Frank, Manfred. 1989. What is neostructuralism? Minneapolis: University of Minnesota Press.

General Motors Corporation. 2007. Our message: 2005/2006 corporate responsibility report. Detroit: General Motors: The Public Policy Center.

Hart, Stuart L., and Mark B. Milstein. 1999. Global sustainability and the creative destruction of industries. Sloan Management Review 41, no. 1: 23-34.

Heiskanen, Eva, and Mika Pantzar. 1997. Toward sustainable consumption: Two new perspectives. Journal of Consumer Policy 20, no. 4: 409-42.

Hjelmslev, Louis. 1943. Prolegomena to a theory of language. Madison: University of Wisconsin Press.

Holt, Douglas B. 1997. Poststructuralist/postmodern lifestyle analysis: Conceptualizing the social patterning of consumption in postmodernity. Journal of Consumer Research 23, no. 4: $326-50$.

- 2002. Why do brands cause trouble? A dialectical theory of consumer culture and branding. Journal of Consumer Research 29, no. 1: 70-90.

Holt, Douglas B., and Craig J. Thompson. 2004. Man-of-action heroes: The pursuit of heroic masculinity in everyday consumption. Journal of Consumer Research 31, no. 2: 425-40.

Honda Motor Company LTD. 2005. Honda environmental annual report. http://world.honda. com/environment/reports (accessed October 13, 2005).

HybridCars. 2011. Better gas mileage in a Toyota Prius. http://www.hybridcars.com/gas-savingtips/maximizing-mileage-toyota-prius.html.

Kangun, Norman, and Michael J. Polonsky. 1995. Regulation of environmental marketing claims: A comparative perspective. International Journal of Advertising 14, no. 1: 1-24.

Kjellberg, Hans. 2008. Market practices and over-consumption. Consumption Markets \& Culture 11, no. 2: 151-67.

Kozinets, Robert V. 1999. E-tribalized marketing?: The strategic implications of virtual communities of consumption. European Management Journal 17, no. 3: 252-64.

- 2002. The field behind the screen: Using netnography for marketing research in online communities. Journal of Marketing Research 39, no. 1: 61-72. 
Krippendorff, Klaus. 1993. Major metaphors of communication and some constructivist reflections on their use. Cybernetics and Human Knowing 2, no. 1: 3-25.

Lacan, Jacques. 2002. Ecrits. A selection. Trans. Bruce Fink. New York: W.W. Norton.

Levi-Strauss, Claude. 1963. Structural anthropology. New York: Basic Books.

Levy, Sidney J. 1981. Interpreting consumer mythology: A structural approach to consumer behaviour. Journal of Marketing 45, no. 3: 49-61.

Linton, Ralf. 1945. Present world conditions in cultural perspective. In The science of man in world crisis. ed. R. Linton. New York: Columbia University Press.

Maturana, Humberto R., and Francisco J. Varela. 1980. Autopoiesis and cognition: The realization of the living. Dordrecht: D. Reidel Pub. Co.

-. 1992. The tree of knowledge: The biological roots of human understanding. New York: Shambhala.

McCracken, Grant. 1986. Culture and consumption: A theoretical account of the structure and movement of the cultural meaning of consumer goods. Journal of Consumer Research 13, no. 1: $71-84$.

-. 2005. Culture and consumption II: Markets, meaning, and brand management. Bloomington: Indiana University Press.

Mick, David G. 1986. Consumer research and semiotics: Exploring the morphology of signs, symbols, and significance. Journal of Consumer Research 13, no. 2: 196-213.

Miller, David J. 2005. August 30 2005: Hybrid marital woes: Part deux www.hybridcars.com (accessed April 25, 2006).

Muñiz, Albert M. Jr. and Thomas C. O’Guinn. 2001. Brand community. Journal of Consumer Research 27, no. 4: 412-33.

Murray, Jeff B., and Julie L. Ozanne. 1991. The critical imagination: Emancipatory interests in consumer research. Journal of Consumer Research 18, no. 2, 129-44.

Newholm, Terry. 2005. Case studying ethical consumers' projects and strategies. In The ethical consumer, ed. R. Harrison, T. Newholm and D. Shaw, 107-24. London: Sage Publications Ltd.

Nöth, Winfried. 1990. Handbook of semiotics. Bloomington: Indiana University Press.

Pẽnaloza, Lisa, and Mary C. Gilly. 1999. Marketer acculturation: The changer and changed. Journal of Marketing 63, no. 3: 84-104.

Reidenbach, Eric R., and Terence A. Oliva. 1983. Toward a theory of the macro systemic effects of the marketing function. Journal of Macromarketing 3, no. 2: 33-40.

Ringberg, Torsten, and Markus Reihlen. 2008. Communication assumptions in consumer research: An alternative socio-cognitive approach. Consumption Markets \& Culture 11, no. 3: $173-89$.

Saussure, Ferdinand. 1966. Course in general linguistics. New York: McGraw Hill.

Schor, Juliet. 1999. The overspent American: Why we want what we don't need. New York: Harper Perennial.

Smart, Barry. 2010. Consumer society: Critical issues and environmental consequences. London: Sage Publications.

Smith, Toby M. 1998. The myth of green marketing: Tending our goats at the edge of apocalypse. Toronto: Toronto University Press.

Smith, Scott, Dan Fisher, and Jason S. Cole. 2007. The lived meanings of fanaticism: Understanding the complex role of labels and categories in defining the self in consumer culture. Consumption Markets \& Culture 10, no. 2: 77-94.

Srinivasan, Shuba, Koen Pauwels, Jorge Silva-Risso, and Dominique M. Hanssens. 2009. Product innovations, advertising, and stock returns. Journal of Marketing 73, no. 1:24-43.

Stern, Barbara B. 1995. Consumer myths: Frye's taxonomy and the structural analysis of consumption text. Journal of Consumer Research 22, no. 2: 165-86.

-. 1997. Deconstructing consumption text: A strategy for reading the (re)constructed consumer. Consumption Markets \& Culture 1, no. 4: 303-423.

Thompson, Craig J., Aric Rindfleisch, and Zeynep Arsel. 2006. Emotional branding and the strategic value of the doppelganger brand image. Journal of Marketing 70, no. 1: 50-64.

Toyota Motor Corporation. 2005. Environmental and social report 2005. Toyota City: Environmental Affairs division. http://www.toyota.co.jp (accessed September 20, 2006).

Valor, Carmen. 2008. Can consumers buy responsibly? Analysis and solutions for market failures. Journal of Consumer Policy 31, no. 3: 315-26. 
Varey, Richard J. 2000. A critical review of conceptions of communication evident in contemporary business and management literature. Journal of Communication Management 4, no. 4: $328-40$.

Varey, Richard J. 2010. Marketing means and ends for a sustainable society: A welfare agenda for transformative change. Journal of Macromarketing 30, no. 2: 112-26.

Welford, Richard. 1997. Hijacking environmentalism: Corporate responses to sustainable development. London: Earthscan.

Žižek, Slavoj. 2007. How to read Lacan. New York: W.W. Norton. 